AFCRC-TN-57-376

ASTIA DOCUMENT No. AD117078

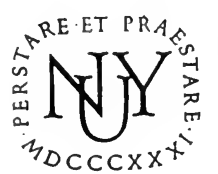

NEW YORK UNIVERSITY

Institute of Mathematical Sciences

Division of Electromagnetic Research

RESEARCH REPORT No. EM-104

\title{
Acoustic Torques and Forces on Disks
}

\author{
JOSEPH B. KELLER
}

CONTRACT No. AF 19(604)1717

APRIL, 1957 

NEW YORK UNIVEFSITY

Institute of Mathematical Sciences

Division of Electromagnetic Fesearch

Research Feport No. EM-104

ACOUSTIC TORQUES AND FORCES ON DISKS

Joseph B. Keller

$\frac{\text { Lozeph f.Kaller }}{\text { Josern B. Keller }}$

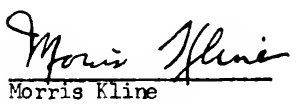

Project Director

April, 1957

The research reported in this document has been sponsored by the Air Force Cambridge Research Center, Air Research and Development Command, under Contract No. AF 19(604)1717.

New York, 1957 



\section{Abstract}

The time-average forces and torques exerted by a plane sound wave upon fixed rigid disks of various shapes are calculated. Results are given for disks bounded by smooth closed convex curves. These results are then specialized to ellipses and circles. Results are also given for infinitely long thin strips. The results are all valid for $k a$ large, where $k=\frac{2 \pi}{\lambda}$, $\lambda$ being the wavelength and a being a typical dimension of the disk. The oscillatory behavior of the torque as a function of $\mathrm{ka}$ and the occurrence of numerous equilibrium positions are interesting consequences of these calculations.

\section{Table of Contents}

\section{Page}

1. Introduction 1

2. The torque on a strip 3

3. The torque on a circular disk 6

Appendix 9

References 13

Figures 15 



\section{Introduction}

When a sound wave strikes an object it exerts a periodic force and torque on the object. In this paper we calculate the mean values of these quantities for certain objects which are thin, rigid and immobile. We call such objects disks. We will consider disks whose rims are smooth closed comex curves, and also disks which are infinitely long strips. The circular Payleigh disk[I] is included. Our results are based upon the 'geometrical theory of diffraction'[2], a new method for solving diffraction problems. This method applies to situations in which the wavelength $\lambda$ is small compared to the obstacle dimensions. However it also works well for wavelengths as large as the obstacle This defines the range in which our present results apply; note that high-frequency sound is included in this range.

Nost of the previous theoretical work on this subject has dealt with the low-frequency case, in which the wavelength is large compared to the obstacle dimensions. W. Konig [3] calculated the torques on an ellipsold and on a circular disk as well as the attractive or repulsive force between two spheres [4] in the limit of infinite wavelength. M. Kotani ${ }^{[5]}$ extended the calculation of the torque on a circular disk to include several powers of $\lambda^{-1}$. L. V. King [6] calculated the force on a sphere to several terms in $\lambda^{-1}$. He also calculated to the same order the force on a circular disk dus to a normally incident, nlane wave, taking account of the motion of the disk [7]. This same force was measured by $R$. $W$. Boyle and J.F. Lehmann[9]. King [s] al so treated the torque on a circular disk, as did Kotani, but took account the disk's own motion, again to several torms in $\lambda$. Wood [10] also indicated how the torque on a circular disk is modified by ils motion and checked his results by experimenting on disks in water. N. Kawai [II] extended the calculation of the torque on a circular disk to somewhat smaller values of $\lambda$. He found that the torque reversed in sense, i.e. changed sign, when 
$\lambda$ became less than about .4 of the disk circumference. H. Ievine [12] obtained an expression for the force on a circular disk due to a normally incident plane wave. It is valid for long waves and is apparently also quite good for short ones. He also determined the torque on an infinitely long strip for short wavelengths [13]. This torque oscillates around the value zero as $\lambda$ varies.

The present calculation begins with two formulas for the force and torque, given without proof by H. Levine and J. Schwinger [14]. The first of these is

$$
F=\frac{p^{2}}{2 p_{0} c^{2}} \cos \alpha \sigma(a) .
$$

In (1) F denotes the normal force on a disk due to an incident plane wave of (real) pressure amplitude $P, a$ is the angle between the normal to the disk and the direction of propagation of the incident wave, $\sigma(\alpha)$ is the scattering cross section of the disk for this direction of incidence, $\rho_{0}$ is the density of the surrounding medium and $c$ is the sound speed in it. Equation (1) applies to an infinitely long strip if $F$ and $\sigma$ are defined to be the force and scattering cross section per unit length.

The formula for the torque is, in modified notation [14],

$$
T=-\frac{p^{2}}{\rho_{0} \omega c} \operatorname{Re}\left\{\rho_{\phi}(\alpha, 0, \alpha)\right\} \text {. }
$$

In (2) $T$ is the torque around an axis perpendicular to the plane containing the direction of propagation of the incident plane wave and the normal to the disk. If this axis is the z-axis then the propagation direction 11 es in the $x y$-plane and the disk lies in the yz-plane. The angle between the propagation direction and the positive $x-a x d s$ is denoted by $a$. Then $P f(\varnothing, 0, a)$ is the complex amplitude of the wave scattered in a direction in the $x y$-plane making the angle $\phi$ with the positive $x$-axis. The angular frequency of the incident vave is $\infty$ and the torque I is positive if it tende to inerease $a$. 
To make the above definitions more precise we note that the incident pressure $p_{0}$ and the ocattered pressure $p_{s}$ are given by

$$
\begin{aligned}
& p_{0}=\operatorname{Re}\left\{P e^{i k(x \cos a+y \sin \alpha)-i \omega t}\right\} \\
& p_{s} \sim \operatorname{Re}\left\{P f(\phi, x, a) \cdot \frac{-k e^{i(k r-\omega t)}}{2 \pi r}\right\}
\end{aligned}
$$

If the disk is an infinitely long strip parallel to the $z$-axis, $f_{\phi}(\alpha, 0, a)$ in (2) must be replaced by $f_{\phi}(\alpha, a)$ which is defined by

$$
p_{s} \sim \operatorname{Re}\{P f(\varnothing, \alpha)\}-\sqrt{\frac{k}{2 \pi r}} e^{i\left(k r+\frac{\pi}{4}-\omega t\right)} .
$$

Furthermore $\mathrm{T}$ then denotes torque per unit length.

Equations (1) and (2) are derived in the Appendix to this paper for both finite disks and infinite strips. The derivation is patterned after that of H. Levine, who derived (2) for the case of an infinite strlp [13] and (1) for finite disks with $\alpha=0$ [12]. Equation (1) for finite disks with $\alpha=0$ also follows from an identity derived by P.J. Westervelt $[15],[16]$. This same identity has also been derived by O.K. Mawardi [18] who also gives additional references to work on 'radiation pressure'.

\section{The torque on a strip}

The scattering amplitude $f(\phi, \chi, a)$ or $f(\phi, a)$ for a rigid disk is the negative of the corrosponding amplitude for an aperture of the same size and shape in a soft screen. This applies in the range $0 \leq \phi \leq \frac{\pi}{2}$ and follows from the rigorous form of Babinet's principle (cf. $[17], p .39)$. From this fact and the cross section theorem we fInd that $\sigma(\alpha)=2 \sigma_{a}(\alpha)$, where $\sigma_{\alpha}(\alpha)$ is the transmission cross section of the aperture. In a previous article $[2]$ we have determined $f$ and $\sigma_{a}$ for apertures bounded by convex curves and for infinite slits in soft screens. 
Therefore to calculate $F$ for the corresponding disks we need merely insert the value of $2 \sigma_{a}$ into (1). For a strip of width $2 a$ we obtain from (27) of [2]

(6) $F=\frac{2 a P^{2}}{\rho_{0} c^{2}}\left\{\cos ^{2} a-\frac{\cos a}{2 \pi^{1 / 2}(k a)^{3 / 2}}\left[\frac{\cos \left[2 k a(1-\sin a)-\frac{\pi}{4}\right]}{1-\sin a}+\frac{\cos \left[2 k a(1+\sin a)-\frac{\pi}{4}\right]}{1+\sin a}\right]\right\}$.

At normal incidence $(\alpha=0)$ this becomes

(7) $F=\frac{2 a p^{2}}{\rho_{0} c^{2}}\left\{1-\frac{\cos \left(2 k a-\frac{\pi}{4}\right)}{\pi^{1 / 2}(k a)^{3 / 2}}\right\}$.

For a disc of radius a we find from (64) of [2]

(8) $F=\frac{\pi a^{2} p^{2}}{p_{0} c^{2}}\left\{\cos ^{2} \alpha-\frac{1}{\pi(k a)^{2}(\sin a)^{1 / 2}}\left[\frac{\sin [2 k a(1-\sin \alpha)]}{(1-\sin \alpha)^{1 / 2}}-\frac{\cos [2 k a(1+\sin \alpha)]}{(1+\sin a)^{1 / 2}}\right]\right\}$

If $a=0$ we obtain from (47) of [2], instead of (7),

(9) $F=\frac{\pi a^{2} p^{2}}{\rho_{0} c^{2}}\left\{1-\frac{2 \sin \left(2 \mathrm{ka}-\frac{\pi}{4}\right)}{\pi^{1 / 2}(\mathrm{ka})^{3 / 2}}\right\}$.

Since other formulas and some graphs of $\sigma_{a}$ are given in [2] we will not consider $F$ any further.

To calculate $T$ from (2) we must compute $-\mathrm{Fe}\left\{f_{\phi}\right\}$ and evaluate it in the forward direction $\varnothing=a, x=0$. Let us first consider the case of a strip of width $2 a$ with the z-axis at its center. From $[2],-f=f_{s}+f_{m}$ where $f_{s}$ results from rays singly diffracted at the edges of the strip and $f_{m}$ results from multiply diffracted rays. Upon using (23) and (33) of [2] and observing that due to a difference in notation the forward direction is at $\varnothing=-\alpha$, we find (10) $\operatorname{Re}\left\{f_{s_{\phi}}(-a, a)\right\}=-\frac{\sin \alpha}{2 k \cos ^{2} \alpha}$, 
(II) $f_{m_{\varnothing}}(-a, a)=\left[4 \pi j k a e^{-4 i k a}+1\right]^{-1}\left[k^{-1} \sec \left(\frac{\pi}{4}-\frac{a}{2}\right) \sec \left(\frac{\pi}{4}+\frac{a}{2}\right) \tan \left(\frac{\pi}{4}+\frac{a}{2}\right)\right.$

$$
\begin{aligned}
& -2 i k a) \frac{\sqrt{\frac{\pi a}{k}}}{k}\left\{e^{-1\left[2 k a(1-\sin a)+\frac{\pi}{4}\right]}\left[\cos a-\frac{1}{2 i k a} \tan \left(\frac{\pi}{4}-\frac{a}{2}\right)\right] \sec ^{2}\left(\frac{\pi}{4}-\frac{a}{2}\right)\right. \\
& \left.\left.-e^{-i\left[2 k a(1+\sin a)+\frac{\pi}{4}\right]}\left[\cos a-\frac{1}{2 i k a} \tan \left(\frac{\pi}{4}+\frac{a}{2}\right)\right] \sec ^{2}\left(\frac{\pi}{4}+\frac{a}{2}\right)\right\}\right] .
\end{aligned}
$$

From (11), retaining only the leading terms in $(\mathrm{ka})^{-1}$, we obtain

(12) $\operatorname{Re}\left\{f_{m_{\phi}}(-a, a)\right\} \sim-\left(\frac{a}{\pi k}\right)^{1 / 2} \frac{\cos a}{2}\left[\frac{\cos \left[2 k a(1+\sin a)-\frac{\pi}{4}\right]}{\cos ^{2}\left(\frac{\pi}{4}-\frac{a}{2}\right)}-\frac{\cos \left[2 k a(1-\sin a)-\frac{\pi}{4}\right]}{\cos ^{2}\left(\frac{\pi}{4}+\frac{c}{2}\right)}\right]$.

According to (10), $f_{s}$ contributes to $T$ a term of order $k^{-1}$ while (12) shows that $f_{m}$ contributes a term of order $k^{-1 / 2}$. Therefore the main contribution to $T$ comes from $f_{m}$ and it is, according to (2) and (12),

$$
T \sim \frac{a^{2} p^{2}}{p_{0} c^{2}} \frac{\cos a}{\sqrt{\pi}(k a)^{3 / 2}}\left[\frac{\cos \left[2 k a(1-\sin a)-\frac{\pi}{4}\right]}{1-\sin a}-\frac{\cos \left[2 k a(1+\sin a)-\frac{\pi}{4}\right]}{1+\sin a}\right] .
$$

This same result, which applies for $a \neq \frac{\pi}{2}$, has also been obtained by H. Levine [13]. The first correction to it can be obtained from (10) and further corrections from (11). The result (13) can be obtianed merely by taking account of the two doubly diffracted rays, rather than of all multiply diffracted ones. It is surprising that these doubly diffracted rays yield a larger contribution to the torque tran do the singly diffracted rays. The torque (13) is similar in form to the second term in (6).

From (13) we see that for fixed values of a and $\mathrm{P}^{2} \mathrm{a}^{2} / \rho_{0} c^{2}$ the torque tends to zero like $(\mathrm{ka})^{-3 / 2}$, but in an oscillatory manner. The force $F$, on the other hand, tends to a finite limit. Therefore for large ka the force is much 
larger than the torque, which is fust the reverse of the behavior at small ka. For fixed values of $\mathrm{P}^{2} \mathrm{a}^{2} / \rho_{0} \mathrm{c}^{2}$ and of $\mathrm{ka}$, the torque is an oscillatory odd function of $a$. It vanishes for certain values of a which determine the equilibrium positions of a strip which is free to rotate around the z-axis. These equilibria are stable if $T_{\alpha}<0$ and unstable if $T_{\alpha}>0$, so they are alternately stable and unstable. To find these values we may rewrite (13) in the form

(14) $T \sim \frac{2 p^{2} a^{2}}{\pi^{1 / 2} \rho_{0} c^{2}(k a)^{3 / 2} \cos \alpha}\left[\sin \left(2 k a-\frac{\pi}{4}\right) \sin (2 k a \sin \alpha)\right.$

$$
\left.+\sin \alpha \cos \left(2 k a-\frac{\pi}{4}\right) \cos (2 k a \sin \alpha)\right] \text {. }
$$

Thus the equilibrium values of $a$, other than $a=0$, are the solutions of the equation

$$
\frac{\tan (2 k a \sin a)}{2 k a \sin a}=-\frac{\cot \left(2 k a-\frac{\pi}{4}\right)}{2 k a}
$$

The stability of $a=0$ is determined by the sign of

(16) $T_{a}(0)=\frac{2 p^{2} a^{2}}{\pi^{1 / 2} \rho_{0} c^{2}(k a)^{3 / 2}}\left[2 k a \sin \left(2 k a-\frac{\pi}{4}\right)+\cos \left(2 k a-\frac{\pi}{4}\right)\right]$.

Although, as is well known, $a=0$ is stable for ka very small (when our formulas do not apply), we see that it becomes alternately unstable and stable as ka increases. When $a=0$ becomes unstable, there are two stable equilibria near $a=0$.

3. The torque on a circular disk

In order to calculate $T$ for a disk bounded by a smooth censex curve we begin with $(57)$ of [2]. This equation gives $u_{d}$, the field which 
results when an incident field of unit amplitude is doubly diffracted at the edges of the complementary aperture in a soft screen. Therefore when the spherical wave factor is removed, this equation will yield $-f_{d}(\phi, x, a)$, the contribution of doubly diffracted rays to the scattered amplitude. By using this result in (2) we will obtain the contribution of such rays to the torque. It is to be expected that, as in the case of the strip, these rays will yleld the main contribution to the torque. Therefore we will not bother to evaluate the contributions of other rays.

Since the leading term in $k$ of the derivative $f_{d_{\phi}}$ comes from the phase factor, it suffices to evaluate the amplitude in (57) in the forward direction $\phi=a$ before differentiating. Then (57) becomes (61), in which only the exponent depends upon $\varnothing$. Upon removing the spherical wave factor we obtain

(17) $f_{d}(\phi, x, \alpha)=\frac{2}{k^{2}} \sum \frac{e^{i k[Y(P)+d+s-r]+i \varepsilon}}{\cos a \sin \beta} \sqrt{\frac{\rho_{F} \rho_{Q}}{d|B|}}$.

The notation is the same as that of [2]. Now we differentiate (17) and insert the result into (2), obtaining

(18) $T=\frac{2 P^{2}}{\rho_{0} \omega^{2}} \sum \frac{[Y(P)+d+s-r] \phi}{\cos \alpha \sin \beta} \sqrt{\frac{\rho_{P} P_{Q}}{d|B|}} \sin \{k[Y(P)+d+s-r]+\varepsilon\}$.

Let us apply (18) to a disk which is symmetric in the y-and z-axes. Then only two doubly diffracted rays go in the forward direction. They come from rays incident at the two points on the edge in the plane $z=0$. Furthermore $\beta=\frac{\pi}{2}, \rho_{P}=\rho_{Q}=\rho, Y_{\phi}(P)=d_{\phi}=0, \operatorname{s-r}= \pm \frac{d}{2} \sin \phi, \mathbf{Y}(P)= \pm \frac{d}{2} \sin \alpha$, and $B=(I \pm \sin \alpha)\left(2 \rho_{P}-d[1 \pm \sin \alpha]\right)$. Here the positive signs apply to one ray and the negative signs to the other. Inserting these values into (18) yields 
(19) $T=\frac{p^{2} d^{1 / 2} \rho}{\rho_{0} \omega^{2}}\left[\frac{\sin \left[k d(1+\sin \alpha)+\varepsilon_{+}\right]}{(1+\sin \alpha)^{1 / 2}|2 \rho-d(1+\sin \alpha)|^{1 / 2}}-\frac{\sin \left[k d(1-\sin \alpha)+\varepsilon_{-}\right]}{(1-\sin \alpha)^{1 / 2}|2 \rho-\alpha(1-\sin \alpha)|^{1 / 2}}\right]$

In (19) $d$ is the width of the disk along the $y$-axis and $\rho$ is the radius of curvature of the edge at the $y$-axis. The symbol $\varepsilon_{ \pm}$is equal to $-\frac{\pi}{2}$ or 0 accordIng as $2 p-d(I \pm \sin \alpha)$ is negative or positive.

Suppose the disk is an ellipse with major axis of length $2 a$ along the $y$-axis and minor axis of length $2 \varepsilon a$ along the z-axis. Then $d=2 a$ and $\rho=\varepsilon^{2} a$. Since $\varepsilon<1$ it follows that $2 p-d(1+\sin \alpha)=2 a\left(\varepsilon^{2}-1-\sin \alpha\right)<0$, so $\varepsilon_{+}=-\frac{\pi}{2}$, while the value of $\varepsilon_{-}$depends upon the sign of $\varepsilon^{2}+\sin \alpha-1$. Let us suppose that this is positive, which requires $\sin \alpha>1-\varepsilon^{2}$. Then $\varepsilon_{-}=0$, and (19) becomes

(20) $T=-\frac{\varepsilon^{2} p^{2} a^{3}}{\rho_{0} c^{2}(k a)^{2}}\left[\frac{\cos [2 k a(1+\sin a)]}{(1+\sin a)^{1 / 2}\left(1+\sin a-\varepsilon^{2}\right)^{1 / 2}}+\frac{\sin [2 k a(1-\sin a)]}{(1-\sin a)^{1 / 2}\left(-1+\sin a+\varepsilon^{2}\right)^{1 / 2}}\right]$.

In the special case of a circle, $\varepsilon=1$, so $\sin a>1-\varepsilon^{2}=0$ and (20) yields

(21) $T=-\frac{p_{a}^{2}{ }^{3}}{\rho_{0} c^{2}(k a)^{2}(\sin a)^{1 / 2}}\left[\frac{\cos [2 \mathrm{ka}(1+\sin a)]}{(1+\sin a)^{1 / 2}}+\frac{\sin [2 \mathrm{k} a(1-\sin a)]}{(1-\sin a)^{1 / 2}}\right]$.

This result applies for $a \neq 0, \frac{\pi}{2}$. The torque tends to zero like $(k a)^{-2}$ as ka becomes infinite, but in an oscillatory mamer. For fixed ka there are equilibrium values of a which are alternately stable and urstable. They are obtained by setting $T=0$ in (21). As in the case of the strip, the torque is larger than the force on the circular disk for ka very small, but the reverse is true for ka large. 


\section{APPENDIX: Derivation of the Basic Formulas (1) and (2)}

Let us denote by $\hat{\mathbf{Y}}(\mathrm{x}, \mathrm{t})$ the real time dependent velocity potential of an acoustic motion at the point $x=(x, y, z)$. The pressure $p(x, t)$, to terms of second order in $\hat{\mathbf{y}}$, is given by $[8]$

$$
p=p_{0}+\rho_{0} \hat{\mathbf{Y}}_{t}+\frac{\rho_{0}}{2}\left[c^{-2} \hat{\mathbf{Y}}_{t}^{2}-(\hat{\mathbf{Y}})^{2}\right]
$$

Here $p_{0}$ and $\rho_{0}$ denote respectively the constant pressure and density in the undisturbed medium and $c$ is the sound speed in it. If the motion is periodic (harmonic) in time with angular froquency $\omega$, then $\hat{\mathbf{Y}}$ can be expressed in terms of the complex time independent velocity potential $\mathbf{I}(\boldsymbol{x})$ by the relation

$$
\hat{\mathbf{Y}}(x, t)=\operatorname{Re} e^{-i \omega t} \mathbf{Y}(x) .
$$

Upon inserting (A2) into (AI) and averaging over a period, we find that the average pressure $\bar{p}(x)$ is given by

$$
\bar{p}(x)=p_{0}+\frac{\rho_{0}}{4}\left[k^{2} \nabla^{*}-\nabla \Psi \cdot \nabla^{*}\right] .
$$

In (A3) $\mathrm{k}=\frac{\omega}{\mathrm{c}}$.

The time average force $F$ in the positive $x$-direction on a disk $S$ lying in the yz-plane is

$$
F=\int_{S}[\bar{p}(0-, y, z)-\bar{p}(0+, y, z)] d y d z .
$$

The time average torque $T$ around the $z$-axis is

$$
T=\int_{S} y[\bar{p}(0-, y, z)-\bar{p}(0+, y, z)] d y d z .
$$

We will now express $F$ and $T$ in terms of by means of (A3). However, we first note that $\mathbf{Y}_{\mathbf{X}}=0$ on the disk since it is rigid and immobile. We also make use 
of the following well-known formula (cf. [17], p. 39):

$$
\Psi(0-, y, z)+\Psi(0+, y, z)=2 \Psi 0(0, y, z)
$$

Here $y_{0}(x)$ is the velocity potential of the incident wave, which we assume to be

$$
I_{0}(x)=\frac{P}{\rho_{0} \omega} e^{i k(x \cos \alpha+y \sin \alpha)} .
$$

The real constant $P$ denotes the pressure amplitude of the incident wave and $a$ is the angle between the direction of propagation of the incident wave and the normal to the disk.

When (A3) is inserted into (A4) and (A5) certain differences occur in the integrands. By means of the preceding observations these differences can be simplifled to

$$
\begin{aligned}
& \left(\bar{Y}^{*}\right)_{-}-\left(\bar{Y}^{*}\right)_{+}=\operatorname{Re}\left(\bar{Y}_{0}^{*} \delta \Psi\right), \\
& \left(\nabla \Psi \cdot \nabla^{*}\right)_{-}-\left(\nabla \Psi \cdot \nabla \Psi^{*}\right)_{+}=\operatorname{Re}\left(\nabla_{2} \bar{Y}_{0}^{*} \cdot \nabla_{2} \delta \Psi\right)=\operatorname{Re}\left(\bar{Y}_{o_{y}^{*}}^{*} \delta Y_{y}\right) .
\end{aligned}
$$

In these formulas the subscript + or - indicates that a quantity is to be evaluated at $x=0+$ or $x=0-$. The operator $\nabla_{2}=\left(\frac{\partial}{\partial y}, \frac{\partial}{\partial z}\right)$ is the gradient in the $\mathrm{yz}-\mathrm{plane}$ and $\delta \mathbf{I}$ is the difference

$$
\delta \Psi(y, z)=I(0-, y, z)-Y(0+, y, z)
$$

When these formulas are used in (AL) and (A5) they become

(AII) $F=\frac{P}{2 \omega} \operatorname{Re}\left\{\int_{S} e^{-i k y \sin \alpha}\left[k^{2} \delta \Psi+i k \sin \alpha \delta \Psi_{y}\right] d y d z\right\}$,

(A12) $T=\frac{P}{2 \omega} \operatorname{Re}\left\{\int_{S} y e^{-i k y} \sin \alpha\left[k^{2} \delta I+i k \sin \alpha \delta \mathbf{y}\right] d y d z\right\}$. 
These formulas simplify further if the second tern in each integral is integrated by parts with respect to $y$ and the fact that $\delta \Psi=0$ at the edge is used. They then reduce to

(A13) $F=\frac{P k^{2} \cos ^{2} \alpha}{2 \omega} \operatorname{Re}\left\{\int_{S} e^{-i k y \sin \alpha} \delta \mathbf{I} d y d z\right\}$,

(AI4) $T=\frac{P}{2 \omega} \operatorname{Re}\left\{\int_{S} e^{-i k y \sin \alpha} \delta I\left[y k^{2} \cos ^{2} \alpha-i k \sin \alpha\right] d y d z\right\}$.

We now make use of the fact that $I$ can be written in terms of $\delta \mathbf{Y}$ as

(AI5) $\quad I(x)=\Psi_{0}(x)-\int_{S} \delta I\left(y^{\prime}, z^{\prime}\right) G_{x^{\prime}}\left(x, y, z ; x^{\prime}, y^{\prime}, 0\right) d y^{\prime} d z^{\prime}$.

In (AI5) $G$ denotes the Groen's function

$$
G\left(x, x^{\prime}\right)=\frac{e^{i k\left|x-x^{\prime}\right|}}{4 \pi\left|x-x^{\prime}\right|}
$$

Let us denote the spherical coordinates of the point $x$ by $(r, \phi, x)$ with the $x-a x d s$ as the polar axis, $\varnothing$ as the co-latitude and $X$ as the azimuth. Then for $r$ large compared to the dimensions of the disk (A15) becomes

(A17) $I(x) \sim \Psi_{0}(x)+\frac{e^{i k r}}{4 \pi r} i k \cos \phi \int_{S} \delta \Psi\left(x^{\prime}, y^{\prime}\right) e^{-i k\left(y^{\prime} \sin \phi \cos x+z^{\prime} \sin \varnothing \sin x\right)} d y^{\prime} d z '$ The coefficient of $-k e^{i k r} / 2 \pi r$ is defined to be the amplitude of the scattered wave corresponding to the incident direction $a$. We write it as

(Al8) $\frac{P}{\rho_{0} \omega} f(\varnothing, X, \alpha)=-\frac{i \cos \phi}{2} \int_{S} \delta Y\left(x^{\prime}, y^{\prime}\right) e^{-i k\left(y^{\prime} \sin \phi \cos x+z^{\prime} \sin \phi \sin x\right)} d y^{\prime} d z^{\prime}$. 
Upon comparing (AI3) and (A14) with (A18) we see that $F$ and $T$ can be written in the form

(A19) $F=-\frac{p^{2}}{\rho_{0} c^{2}} \cos \alpha \operatorname{Im}\{f(\alpha, 0, \alpha)\}$,

(AZO) $\quad T=-\frac{P^{2}}{\rho_{0} \omega c} \operatorname{Re}\left\{f_{\phi}(\alpha, 0, a)\right\}$.

Equation (A2O) is exactly (2) of the Introduction, while (A19) becomes (1) when we make use of the cross-section theorem $[17],-2 \operatorname{Im}\{f(\alpha, 0, \alpha)\}=\sigma(\alpha)$. In case the disk is a strip (or collection of parallel strips) of infinite length, the potential $Y$ is independent of $z$. Therefore the $z$ integration can be omitted in ( $A 17$ - A15) provided that $F$ and $T$ are interpreted as force and torque per unit length in the z-direction. Then $G$ in (AI5) is the two-dimensional Green's function

(A21) $G\left(x, x^{\prime}\right)=\frac{1}{4} H_{0}^{(1)}\left(k\left|x-x^{\prime}\right|\right)$.

Now we denote by $r, \not$ the polar coordinates of $x$, assumed to lie in the plane $z=0$. When $r$ is large compared to the strip width, (A15) becomes

(A22) $\quad I(x) \sim y_{0}(x)+\frac{1}{4}\left(\frac{2}{\pi k r}\right)^{1 / 2} e^{i\left(k r-\frac{\pi}{4}\right)} i k \cos \phi \int_{S} \delta Y\left(y^{\prime}\right) e^{-i k y^{\prime} \sin \phi} d y^{\prime}$. The coefficient of $-(k / 2 \pi r)^{l / 2} e^{i\left(k r+\frac{\pi}{4}\right)}$ is defined to be the amplitude of the scattered wave. We write it as

(A23) $\frac{P}{\rho_{0} \omega} f(\phi, \alpha)=-\frac{i \cos \phi}{2} \int_{S} \delta\left(y^{\prime}\right) e^{-i k y^{\prime} \sin \phi} d y^{\prime}$.

When (A13) and (A14), omitting the $z$ integration, are compared with (A23), 
they are found to be of the form (A19) and (A2O) with $f(a, a)$ and $f_{\not}(a, a)$ in place of $f(a, 0, a)$ and $f_{\phi}(\alpha, 0, a)$.

\section{References}

[1] Lord Rayleigh - Theory of Sound; 2nd ed., Dover publishers, New York, 1945, vol. 2, Sec. 253b, p. 43 .

[2] Keller, J.B. - Diffraction of an aperture, I; New York University, Institute of Mathematical Sciences, Div. of Slectromagnetic Research, Report No. EM-92, June 1956. Also, J.Appl. Phys., March or April, 1957.

[3] Konnig, W. - Hydrodynamisch -acoustische Untersuchungen, Teil 3; Wied. Ann. A. Phys. u. Ch., 43, 43 (1891).

[4] - Hydrodynamisch-acoustische Untersuchungen, Teil 1, Teil 2; ibid., 42, 353 and 549 (1891).

[5] Kotani, M. - Proc. Phys. Math. Soc. Japan, 15, 30 (1933).

[6] King, L.V. - On acoustic radiation pressure on spheres; Proc. Roy. Soc., A 147, 212 (1934).

[7]

[8]

- On acoustic radiation pressure on circular discs: inertia and diffraction corrections; ibid., A153, I (1235).

- On the theory of inertia and diffraction corrections for the Rayleigh disc; ibid., Al53, 17 (1935).

[9] Boyle, R.W. and Lehmann, J.F. - Diffractive reflection and scattering of ultrasonic waves. Their influence on torsion-pendulum measurements of sound intensity; Can. J. Res. 3, 491 (1930).

[10] Wood, A. B. - A correction to the theory of the Rayleigh disc as applied to the measurement of sound-intensity in water; Proc. Phys. Soc. London, 47, 779 (1935).

[1] Kawai, N. - Science Reports of the Tohoku University, $\underline{3}, 210$ (1951).

[12] Levine, H. - Acoustic radiation pressure on a circular disk; Proc. Symp. Appl. Math., McGraw-Hill, New York, 1954, vol. 5, p. 63.

[13] - The torque or. an infinite strip exposed to plane sound waves;

Proc. Camb. Philos. Soc., 53, 234 (1957). 
[1ل] Levine, H., and Schwinger, J. - Radiation force and torque; Phys. Kev., 87, 224 (1952) (abstract).

[15] Westervelt, P.J. - The theory of steady forces caused by sound waves; J. Acoust. Soc. Amer., 23, 312 (1951). - Acoustic radiation pressure; J. A coust. Soc. Amer., 29, 26 (1957).

[17] Bouwkamp, C.J. - Diffraction theory; Rep. Prog. Phys., 17, 35 (1954).

[18] Mawardi, 0.K. - On radiation pressure in acoustics; J.Phys.Radium, 17, 384-90 (1956). 


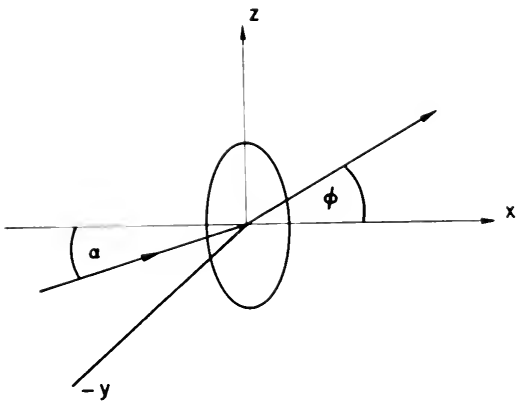

Figure 1

A disk lying in the yz-plane. The direction of propagation of the incident wave lies in the $x y$-plane and makes the angle a with the $x$-axis.

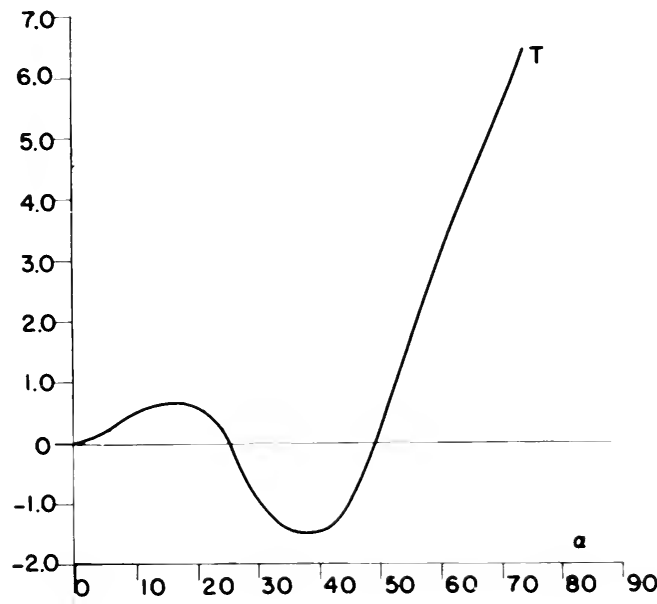

\section{Figure 2}

The torque per unit length $T$ on a strip of width $2 a$ as a function of the angle of incidence $a$ for $k a=5$. The vertical scale is the value of $T\left[\frac{a^{2} p^{2}}{\rho_{0} c^{2} \pi^{1 / 2}(k a)^{3 / 2}}\right]^{-1}$. The curve is based upon equation (13). The values of $a$ at which $T=0$ are equilibrium angles. Those for which $\mathrm{T}_{a}<0$ are stable and those for which $\mathrm{T}_{a}>0$ are unstable. The curre does not apply near $a=\frac{\pi}{2}$. 


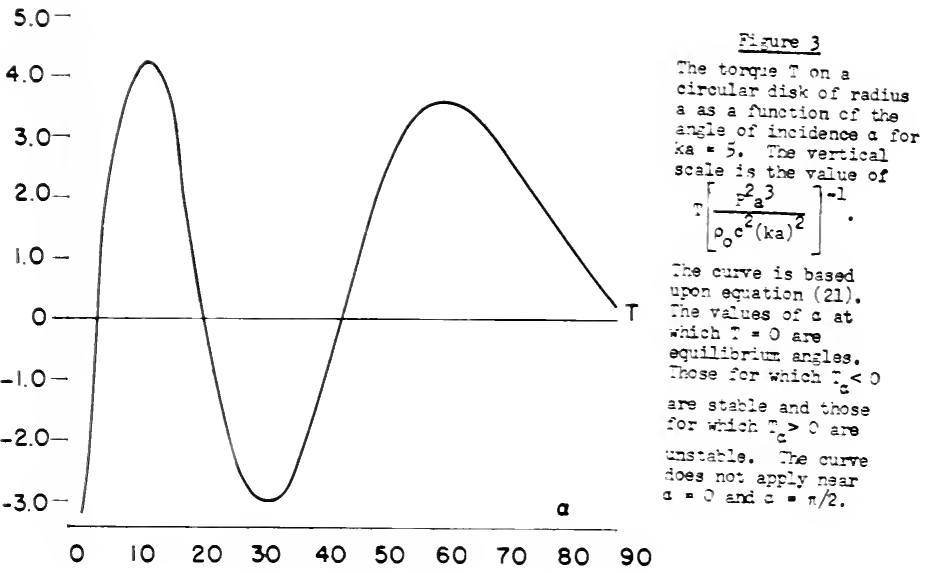

$30-$
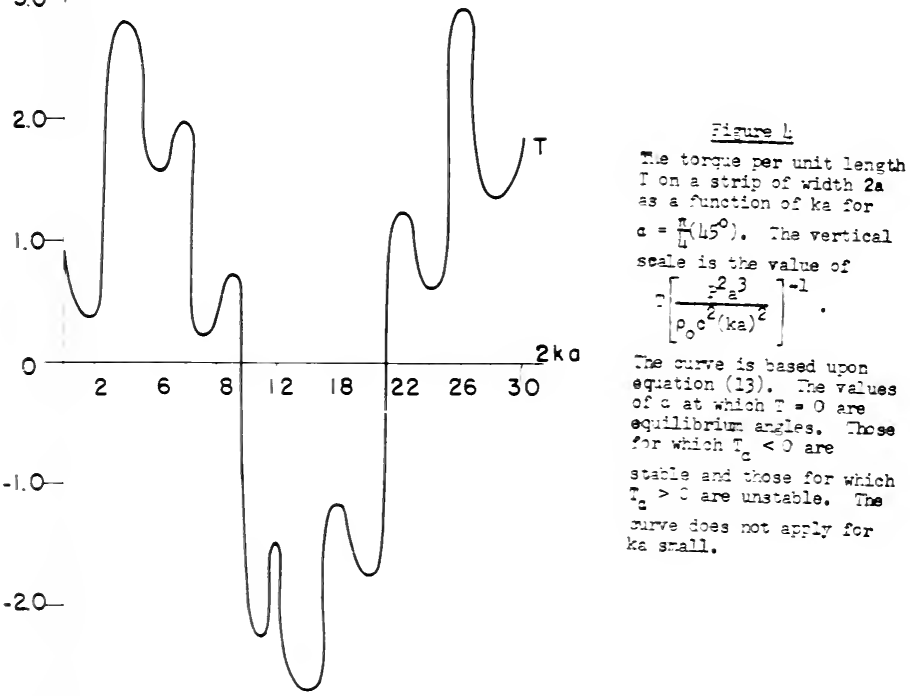


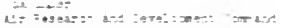

$\therefore$ 50x $23 x$

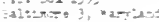

$A: \pm n:=2+$

\section{Tor ande:

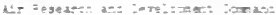

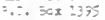 \\ Fa::in: $3,-27: 120$

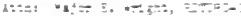

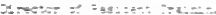

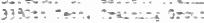 \\ roe.

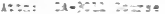

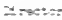

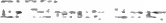

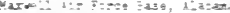 \\ 1::2: $\rightarrow-25$ \\ Z ronander

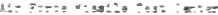

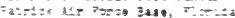

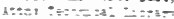

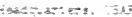

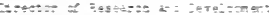

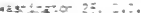

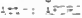

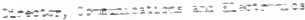

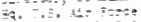

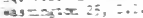

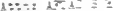

\section{: xma -es}

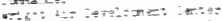

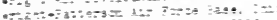

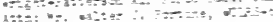

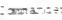

u-

-

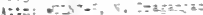

: Mma-cis

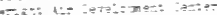

40.

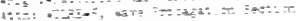

L于 :

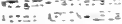

: $2 \pi 592 \div$

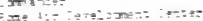

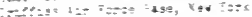

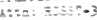

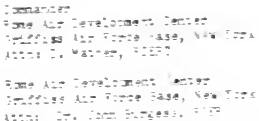

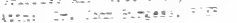

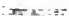

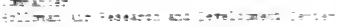
a:

i::s: $=2:$

$\sin 2: 20$

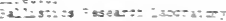

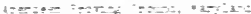

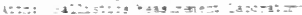

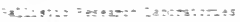

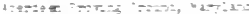

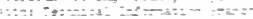

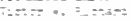

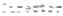

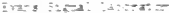

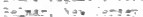

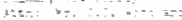

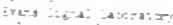

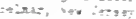

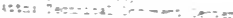

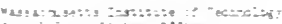

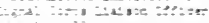

axt

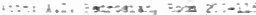

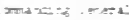

50: I-

\%

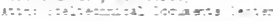

$$
\text { 17\% } 2:-22
$$

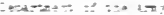

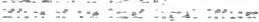

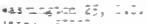

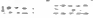

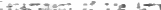

招:

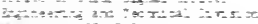

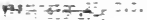

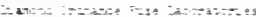

a

A:R土: 4 : Fin, a: ater.

$\because z=?$ :

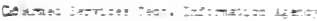

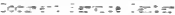

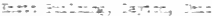

$1=-2,-5 ;-1$

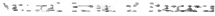

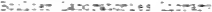

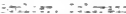

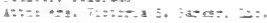

ia:

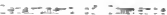

由.13

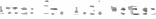

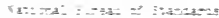

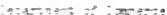

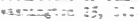

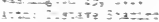

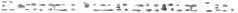

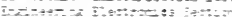

西势-

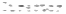

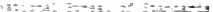

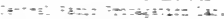

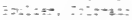

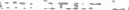

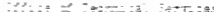

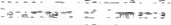

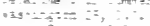

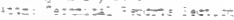

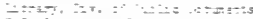

.2. :

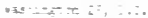

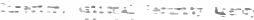

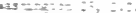

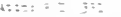

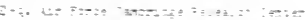

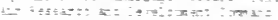

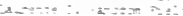

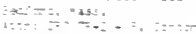

F -

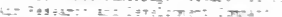

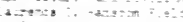

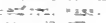

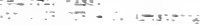

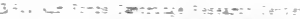

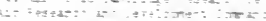

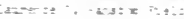

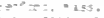

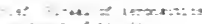

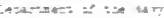

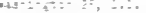

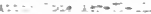

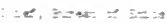

(4T) :

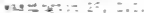

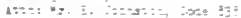

\section{:arer}

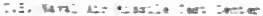

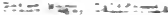

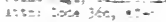

$\therefore$ a $T_{2}:=1-2=10 \rightarrow 1=1$

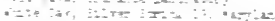

$100:=0$ :

\section{tantres:}

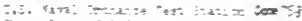

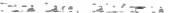

in: : :

$0: \div 1--1=$

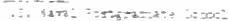

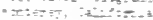

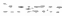

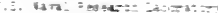

ain...

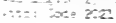

Z:-2:5::

¿. darz: =

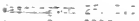

:०-:

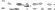

ㄷ.

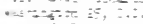

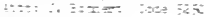

ता स्थ:

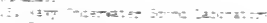

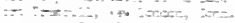

$\because=: \because, \therefore,:=$

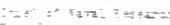

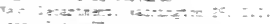

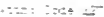

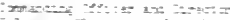

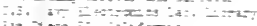

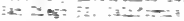

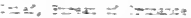

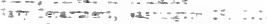

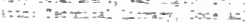

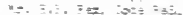

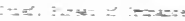

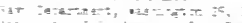

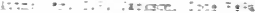

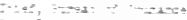

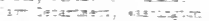

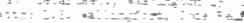

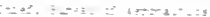

arant:

Tाय

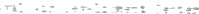

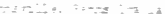

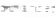

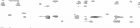

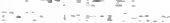

-

-... 
Arborne Instruments Laboratory, Inc. ito old Country Road

Mineola, New York

Attn: Dr. E.0. Fubini, Director Research and Englnearing DAvioion

Alrcom, Inc.

354 Main Street

Winthrop, Mass.

American Machine and Foundry Company

Electronice DA fleion

1085 Commonwealth Avenue

Boston 15, Mass.

Attnt Mrs. Rita Moravceik, Librarian

Andrew Alford Consulting Engineers

299 Atlantic Avemue

Boston 10, Mass.

Avion Division

ACF Industries, Inc.

800 North Pitt Street

Alexandria, Virginio

Attns Technical Library

Battelle Menorial Institute

$505 \mathrm{King}$ Avenue

Columbus 1, Ohio

Attn; Dr. Bernard H. L1st

Bell Afrcraft Corporation

P.O. Box One, Buffalo 5, N.Y.

Attn: Mrs. J. Mulcahey, Tech. Lit.

Bell Telephone Laboratorzee, Inc. Whippany Laboratory, Whippany, N.J. Attn: Technical Information lib.

Bendix Avi tion Corporation Paclfic DIvlaion, 11600 Sherman Wey

North Hollywood, Cal1f.

Attn: J.R. Breninger, Engr. Librarian

Bendix Radio, Div, of Bendix Avlation Coro. East Joppa Roed, Toweon 4, Maryland

Attn: Dr. D.M. Allieon, Jr. Dir. Engineering and Reeearch

Bjoricsten Research Laboratorlee, Inc. P.0. Box 265

Madieon 1, Wisconein

Attn: F.B. Koregard, Treesurer

Boeing Airplane Compeny

P1lotless Alrcraft DIvieion

Seattle 24, Washington

Attn: R.R. Barber, Library Supervieor

Booing Airplane Company

Wchlte Diviai on Engl neering Library

Whita 1, Kansas

Attn: Kenneth C. Knight, Librarian

Boelng Arplane Company

Seattle Division

Seattle 14, Weahington

Attni E.T. Allen, Llbrary Supervioor

Convali, A Divieion of Deneral Dynamice Coro. Fort worth, Texae

Attni K.O. Brown, DHvilon Research Lib.

Convair, A DHv, of General Dynamice Corp. San Diego 12, Callfornis

Attn: Mrs. Dore B. Burke, Engr. LAb.

Cornell Aero. Lahoratory, Inc.

4455 Geneses Street

Buffalo 21, New York

Attni Elma T. Evans, Librarien

Dalmo Victor Company

A Division of Textron, Inc.

1515 Induetrial Way

Belmont, Caliform

Attn: Mary Ellen Addans, Tech. Lib.

Dorne and Margolin, Inc.

30 Sylvester Stroet

Westbury, Long Island, N.Y.
Douglas Alrcraft Company, Inc.

P.0. Box 200

Long Beach 1, Celifornia

Attn: Engineering Lib. (C-250)

Douglas Alrereft Company, Inc.

827 Laphan Street

E1 Segundo, Californa

Attn: Enginearing Library

Dougles Alreraft Company, Inc.

3000 Ocean Park Boulevard

Santa Monica, California

Attn! Eq. Sec. Ref. F1les, Eq. Eng. A250

Douglas Alrcraft Corporation

2000 North Memorlal Drive

Tulsa, Oklehana

Attn: Engineering Library, D-250

Electronic Comunication, Inc.

St. Paul Street at University Parkway

The Marylander Apartments

Baltimore 18, Maryland

Attn: Dr. D.D. King, Vice-President

Electronic Defense Laboratory

P.0. 3ox 205

Mountain View, Cellfornta

Attn: Library

Electronics Research, Inc.

2300 N. New York A venue

Evansille, Indians

Attn: B.H. Baldridge, Engr. Supervisor

Emerson and Cuming, Inc.

869 Washington Street

Canton, Yass.

Attnt W.R. Cuning

The Emerson Electric Mfg. Company

8100 Florigsant Avenue

St. Louls 21, Miesour

Attn: Mr. E. Breslin, Librarian

Falrchild Atrcraft

DAvision Fairchild Eng. and Airplane Corp.

Hagerstom, Maryland

Attni Lubrary

Farnsworth Electronics Company

Fort vayne 1, Indiana.

Attn: Techntcel Library

Foderel Telecommunication Laboratorle

500 Washington A venue

Nutley 10, New Jersey

Attn: Technical Library

Osbriel glectrontes

Diviaton of Gabriel Company

135 Crescent Road

Noedhan Hel ghts 94, Masa.

Attn: $\mathrm{Mr}$. Steven Golagan

Ooneral Electric Company

Ithacs, New York

Attn: J.9. Travia, Adranced Electront ca Center

General Electric Company

Electronics Park

Syracuse, New York

Attn. Bessie Fletcher, Documente Library Bldg. 3-143 A

General Preciation Laborstory, Inc.

63 Bedf ord Road

Pleasant ville, New York

Attn: Mrs. Mary O. Herbst, Librarian

Goodyear Alrcraft Corp.

1210 Massilion Rosd

Akron 15, Ohio

Attn: Library $D / 120$ Plant A

Oranger Associates

vlectronic Syetems

966 Comerclal Street

Palo Alto, California

Attn: John V.N. Granger, Pres.
Orumar Aircraft Engineering Corp.

Bethpage, Long Island, N.Y.

Attn: Mra. A.M. Gray, Librarian

Engineering Library, Plent No. 5

The Hallicraftere Co.

4 hol West 5 th Avenue

Chicago 24, I11inote

Attn: Mias Kay Lynch, LAbrarian

Hoffman Laboratories, Inc.

3740 South Orand Avenue

Los Angeles 7, Californis

Attn: Englneering Lfbrary

Hughes A1rcraft Co., Antenn Dept.

Microwave Laboratory, Bldg. 12, Pu 2617

Culver City, Californis

Attn: M.D. Adcock

Hughes Alrcraft Co.

Forence and Teale Streets

Culver City, Californte

Attn: Dr. L.C. Van Atta, Aesoc. Dir. Research Laboratories

Hycon Eastern, Inc.

75 Cambridge Parkwoy

Cambridge, Masa.

Attn: Mre. Lois Seulowitz, Tech. Lib.

Internationsl Business Machlnes Corp.

Military Products Division

590 Madieon Avenue

New York 22, New York

Attn: Mr. C.F. McElwain, General Manager

International Business Machines Corp.

Military Products Division

A1rborne Computer Laboratorles

Vestal, New York

Attn: Mr. J.J. Walsh, Dept. 528

International Resistance Company

401 N. Broad Street

Philis jelphia 8, Pa.

Attn: Resarch Library

Jansky and Ba1ler, Inc.

1339 is sconsin Avenue, N.W.

vashingt on ?, D.C.

ittn: Mr. Delmer C. Ports

r. Henry Jasik, Consulting Engr.

298 Shanes Drive,

Brush Hollow Industrial Park

Westbury, New York

Martin Katzin and Company, Consultants

71 lith Street, N.N.

Washington 5, D.C.

Lockheed Aircraft Corp.

Vissile Systems Diviaion

7701 woodley Avenue

Van Nuys, Californis

At.tn: Van Nuys L1b. Bldg. 902

Lockheed Aircraft Corp.

Galifornda Df Fision Engr. Lib.

Dent. 72-25, Plant A-1, Bldg. 63-1

Burbank, Californis

Attn: N.C. harnols

The Glenn L. Mart1n Company

Denver Division

Waterton, Colorado

Attn: Wilitam V. Foley, Test and Reliability

Ma1l No. 2-38

The Glenn L. Martin Company

Baltimore 3, Maryland

Attn: Angr. ILb., Antenna Design Group

maryland Electronic Mf. Corn.

tong Celvert poad

College Park, Marvland

Nathematical Reviews

190 Hope Street

Providence 6, Rhode Island 
The W.L. Mexon Corporation

460 weat 3 hth Street

New York, N.Y.

Attn: Mis Dorothy Clsik

MeDonneli Al reraft Corp.

Lambert Sa1nt-louts Municipal Alrport.

Box 516, St. Louts 3, Misour1

Attn: R.D. Detrich, ingr. Library

Marillan Laboratory, Inc.

Bromville A venue

I powch, Masaschusetts

Attn: Security offcer, Documant Rm.

Melpar, Inc.

3000 Aŕlington Blad.

Falls Church, Va.

Attn: Enginearling Tech. L1b.

M1crowave Develorment Laboratory

$\$ 0$ Broad Street

Babson Park 57, Mass.

Attni N. Tucker, General Maneger

Microwave Radistion Company

17223 South Harilton St.

Tandena, Callforns

Attn: Mr. Morrts J. Ehrlech, Pres.

Noval Industrial pegerve A1rcraft Plant

P.O. Box 590 ?

Dallas, Texas

Attn: Mr. H.S. White, Librarian

Northrop Atrcraft, Inc.

Rawthorne, Callfornds

Attni Mr. E.A. Freitas, Lib. Dept. 3145

Nortb American Aviation, Inc.

12214 Lakowood B1 vd.

Downey, Callfornta

Attni Engr. LAb. 495-115

North American Aviation, Inc.

Los Angeles International Airport

Los Angelos 45, Calif ornt

Attn: Engineering Technical File

Pgge Communications Engineers, Inc.

710 Fourteenth Street, Northwest

Washington 5, D.C.

Ittn: Librartan

Philco Corporstion Res, DAvision Branch Library

4700 Wiss achlekon Avenue

Philadelphis Llh, Pa.

Attn: Mre. Dorothy S. Collins

P1ckard and Eurns, Inc.

$240 \mathrm{Kighland}$ Avenue

Needham $94, \mathrm{~h}$, Mas.

Attn: Dr. J.T. doBettencourt

Polytechnic Rerearch and Dev. Co., Inc. 202 Iillary Street

Broklyn 1, New York

Attni Technical Library

Radiation Engineering Laboratory

Main Street

Mavnard, Mass.

Attni Dr. John Ruse

Radistion, Inc.

P.O. Draver 37

Melbourne, Florida

Attn; Tech. Library, Mr. M.L. Cox, Assistant Project Enj $f$ neer

Radlo Corp. of America

QCA Laboratortes

Rocicy Point, New York

Attni P.S. Carter, Lab. Library

RCA Laboratorles

Davld Sarnoff Regenrch Center

Princeton, New Jersoy

Attnt Migs Fern Cloak, Lib., Res. Library

RCA Defense Electronio Product.

Camden 2, New Jersoy

Attni Clarence A. Junther, Chief Der. Entr. DEP - Bldg. 15, Foor?
(2T1e Promonoldroldige Corporation

5730 Arbor Vitae Streat

Los Anreles 45 , callor rnie

Attn: Mergaret C. Whitmah, Chi or Lib.

Rad10 Frequency and Antema Consultarits

9592 Baltimore Avenue

Collexe Park, Maryland

The Rand Corporation

1700 Main Streat

Sant a Mons ca, Callf ornd a

Attni Library - viat SBNA Lialson Office

Rantec Corporation

Cslabasss, Calufornis

Attn: Grace Keoner, Office Manager

Ravtheon Manufacturing Company

Miaslo Syatems D1vision

Bederd, Mass.

Attn: Mr. Irving Goldstein

Raytheon Manufacturing Company

Wayland Laboratory

wayland, Mass.

Attn: J.E. Walsh, Dept. 8974, Antenna Degi gn Radar

Ravtheon Manufacturing Coropany

Wisul and Laborator

Wayland, Mass.

At tnt Miss Alice G. Anderaon, Lubrarian

Republic Aviation Corporation

Famingdale, Long Island, N.Y.

Attn: R.E. Fidoten, Englneerling Lib.

Rhe ent Manufacturing Company

Research and Development

9236 East Hall Road

Downey, Californla

Attnt J.C. Joerger

Rvan Aeronautical Company

Lindbergh Fleld

San Diego 12, Calif ornis

Attn: Librar

Sage Laboratorles, Inc.

30 Quinan street

wal than 54, Mase.

Sanders Associates, Inc.

95 Canal Street

Nashua, New Hampshíre

Attn: N.R. Hld, Hbrary

Sandia Corporation, Sandia Base

P. . Box 5800, Albuquerque, Nev Mexdco

Attins Classifled Document 01 viajon

Sperry Gyroscope Company

Great Neck, L.I., New York

Attnt Florence is. Turnbull, angr. Lib.

Stenford Research Institute

Menlo Park, Califormis

Attn: Mrs. Beatrice G1bson, Lib.

Engineerlng Document L1b.

Sylvania Electric Producte, Inc.

100 First Avenue

walthan 54 , rass.

Attnt Chsiles A. Thornhll, Reports Lib. walthan Lsborstorles Library

Susteng Laboratorlas Corporation

15016 Ventura Boulevard

Sheman Caks, Californie

Attin: Dr. Wo Hoffman

Technics L Research Group

17 Union Square Weot

Viev York 3, v.Y.

Atti: M.L. Henderaon, Lfbrarian

A.S. Thamas, Inc.

161 Devonshire Street

Boston 10, Mags.

attin: A.S. Thomas, President
Westinghouse Electryc Corp.

2519 Wilkeng Averue

Baltimore 3, Marrland

Attn: Kent M. Mack, Engr. Hib.

Wheal or Laboratories, Inc.

122 Guttar 111 Road

Great Neck, Now York

Attn: Mr. Harold A. Wheeler

Zenth Plastics Corspary

Box 91, Gardera, Callfornia

Attn: Mr. S.S. Oleesky

Library, Geophyaical Institute of tre Univeraity of Alasika

College, Alaska

University of Californd

Berkeley 4 , Callfornde

Attni S. Silver, Prof. Bner. Solonce Diviaion of Elec. Bror. Electrondes Research Lab.

Electronics Research Laboratory Univergity of Californis

332 Cory Hall, Berkeley 4, Cal1f. Attni J.R. Whinnery, Prof.

California Inotitute of Technology Jet Propulsion Laborator

4800 Oak Grove Drive

Pasadena, Californda

Attn: I.E. Newlan

Cal1fornis Institute of Technology

1201 E. Callfornia Street

Pasadena, Californta

Attn: Dr. Charlea H. Papes

Carnegle Institute of Technology Schenley Park

Pittsburkh 13, Pennsylvanis

Attnt Albert E. Noins

Cornell Univereity

School of Electrical Enginarin

Ithecs, New Yor

Attn: Prof. G.C. Dulman

University of Floride

College of Engineerin

Caineaville, Florlda

Attn: Pror. M.H. Latour, Engineering Sciences Lib.

Georgla Institute of Technology Engineering Experiment Station

Atlants, Georgis

Attn: Mrs. J.H. Crosland Georeita Tech. Library

Harvard Undversit

Technical Reports Collaction

Gordon MCKay Library, 303 A Plerce Hal.

Oxford Street, Cambridge 38, Yast.

Attni Mrs. E.L. Hurscimidt, Lib.

Harvard Colloge Observat ory

60 Grden Street

Carabridge, Mass.

Attni Dr. Fred L. winpple

Und vers ty of Illinols

Seriale topt. - 220S Librery

Urbana, I1Lnots

Univereity of Illinols

college of Broinserint

Orbena, Illinola

Attn: Dr. P.E. Yores

Lept. of Electrical Entr.

The Johns Hopkins thi versity

Homevood Cama

Depertment of Phyalcs

Baltinore $1^{R}$, parylan

Attn: Profasor Donald E. Kerr

The Johne Hopdine Univeraity

8621 reors a d venu.

S1lver Sprind, Maryland

Attn: Mr. Georg- L. Selelstad,

Apell od Fhysics Lab. 
Massachusette Inet1tute of Technology Pesearcb Laboratory of Electronica Document Rocm 20B-221

Canbridge 39, Mass.

Messachusetts Inst1tute of Tech.

Lincoln Laboretory

P.C. Box 73

Lexdngt on 73, Mass.

Attn: Henry Straus, Documant Fim. A-229

Dniversity of Michigan

Electronic Defenee Group

Engineering Reaearch Institute

Ann Arbor, Michigan

Attn: J.A. Boyd, Supervisor

The University of Michigan

w1low Run Laboratorles

W110w Run Alrport

Ypellant1, Michigan

Attn: K.M. Siegel, Head

Theory and Analysis Dept.

University of Michigan

Willow Run Laboratoriea

Engineerlac Research Institute

WH1low Run Airport

Ypsilant1, Michigan

Attn: Librarian

The Univeraity of Minnesota

Minneapolys 14 , Minnesots

Attn: Mr. Robert H. Stum, LAbrary

Northwestern University

Microwave Laboratorles

Evanston, IIlinols

Attn: Frof assor R.E. Beam

Ohio State Univereity

Research Foundation

Coinmbe 10, Ondo

Attn: Dr. T.E. Tice Dept. of Electrical ingr.

The University of $0 \mathrm{klahama}$

Norman, Oklahoma

Attn: Prof. C.L. Farrar

Chairman Electrical Engr.

Polytechnic Institute of Brooklyn

Microwave Research Inatitute

55 Johnaon Street

Brooklyn 1, New York

Attn: Dr. A,A. Olinar

Polytechnic Inet1tute of Brooklyn

Microwave Research Inat1tute

55 Johneon Street

Brooklyn 1, New York

Attn: Mr. A.E. Leenmel

Syracuae University

Research Institute

Collendale $D-6$

Syracuse 10, New York

Attn: Dr. C.S. Grove, Jr. Director of Engr. Research

The Univeraity of 'lexas

Electrical Engr. Research Lab.

P. Box 8026, University Station

Austin 12, Texas

Attn: J.R. Gerhardt, Aasistant Dir.

The University of Texas

Defense Research Lab.

Alatin 12, Texas

Attn: Claude W. Horton, Phys. Lib.

The Univarsity of Toronto

Department of Electrical Engineering

Toronto, Canada

Attn: Prof. G. Sinclair

LTI Research Foundation

P.0. Box 709

Lowell, Mass.

Attn: Dr. Charles R. Mingins

University of Waghington

Dept. of Ejectrical Enginering

Seatt le 5, Washington

Attn: G. Held, Associate Professor
Electronics Division

Pand Corporation

1700 Mein Street

Santa Monica, Celifornd

Attn: Dr. Robert Kalaba

National Bureeu of Standards

Washington, D.C

Attn: Dr. W.K. Saunders

Applied Mathematice and Statistics Lab.

Stanford Oni versi ty

Stanford, Callf ornie

Attn: Dr. Albert H. Bowker

Dept. of Physics and Aatronomy

Michigan State Uni versity

East Lansing, Michigan

Attn: Dr. A. Leitner

Ionsphere Research Laboratory

Pannaylvania State College

State Collage, Pennaylvania

Attn: Prof. A.H. Waynick, Di rector

Institute of Mathematical Sciences

25 Waverly Place

New York 3, New York

Attn: Mrs. JoAn Siegal, Librarion

School of Electrical. Engineering

Purdue University

Lafoyett $\theta$, Indiana

Attn: Professor F.V. Schultz

University of Tennessee

Knoxville, Tennessee

Attn: Dr. Fred A. Flcken

Califomia Institute of Tech.

$1201 \mathrm{E}$. Californte Straet

Pasedena, Californta

Attn: Dr. A. Erdelys

Wayme University

Detro1t, Michigan

Attn: Professor A.F. Stevenson

Mathemat1cs Department

Stanford University

Stanford, Californi a

Attn: Dr. Harold Levine

University of Minnesota

Minneapolis 14, Minnesota

Attn: Prof. Paul C. Rosenbloom

Department of Mathematics

Uni versity of Pennsylvanie

Philadelphia L, Pannsylvanie

Attn: Professor Bernard Epatein

Applied Physics Laboratory

The Johns Hopkins University

8621 Georgia Avenue

Silver Sprin, Maryland

Attn: Dr. B.S. Gourary

(2)Exchange and Gift Division

The Library of Congreas

Washington 25, D.C.

Electrical Englneerin Dept.

Massachusetta Institute of Technology Cambridge 39, Massachusetts

Attn: Dr. L.J. Chu

Nuclear Development Associates, Inc.

5 New Streat

White Plains, New York

Attn: Library

Labenon Valley College

Annville, Pennsylvania

fttn: Prof. B.H. Bissinger

Dept. of Physics

University of Pittsburgh

Thaw Hall

Pittsbur h 13, Pa.

Attn: Dr. Edward Gerjuoy

Dept. of Physics

Amherst Colleze

Anherst, Massachugetts

Attn: Dr. Arnold Arons
Californta Institute of Tech.

Electrical Englneering

Pasadena, Califarnia

Attn: Dr. Zohrab A. Kaprielian

Dr. Rodran Doll

209 A Emmet Street

Ypsilant1, Michigan

Callfornie Ingtitute of Technology

Pasadena 4, Calif ornia

Attn: Mr. Calvin WH cox

Yr. Robert Brockhurst

Woods Hole Oceanographlc Institute

Woods Hole, Massachusetts

National Bureau of itandards

Soulder, Colorado

Attnt Dr. R. Gallet

Mrs. Jane Scanlon

$22 \mathrm{~L}=0367 \mathrm{th}$ Avenue

Bayside 64 , New York

Dr. Solomon L. Schwabel

3689 Louts Rosd

Palo Alto, Californta

Eastern Technical Associates

38 Main Street

Hest1ng s-Cn-lludson, New York

Attn: Dr. Bernard Lippmann

University of Minnesota

The University Library

Minneapolis $\mathcal{L}_{4}$, Minnesota

Attnt Exchange Divlaion

Professor Bernard Friedman

55 Hill top Avenue

New Rocheile, New York

Lincoln Laboratory

Massschuaetts Inst1tute of Tech.

P.C. Box 73

Lexdngton 73, Masa chusetts

Attn: Dr. Shou Chin Wang, Pun. C-351

Melpar, Inc.

3000 Arlington Boulevard

Falls Church, Vir inia

Attn: Mr. K.S. Kelleher, Section Head

Antenne Laboratory, ERD

Hq. Alr Foree Cambridge Res. Center

Laurence G. Hanscon Fyeld

Bedford, Massachusetts

Attn: Nelson A. Logan

Electronl cs Research Directorate

Hq. Air Force Cambridge Pies. Center

Laurence $\mathrm{O}$. Hanscom Fleld

Bedford, Massachusetts

Attn: Dr. Philip Newman, CRRK

Hq. Alr Force Cambridge Res. Center

Laurence G. Hamscon Fleld

Bedford, Massachusetts

Attn: Mr. Francis J. Zucker

Crosley AVCo Res. Labs.

257 Crescent Street

Waltham, Massachusett

Attn: Mr. N.C. Gerson

Hoffman Labs., Inc.

Advanced Development Section

3761 South H111 Street

Los Angeles ?, Calif.

Attn: Dr. Richand B. Barrar

Columbia University

Hudson Laboratories

P.C. Box 239

145 Palisade Street

Dobbs Ferry, New York

Attn: Dr. M.W. Johnson

Institute of Fluid Dynamtes

and Applied Math, Univ. of Maryland

College Park, Maryland

Attn: Dr. Elliott Montroll 
Dept, of Electrical Engineerine washington Und versity

Satnt Louls 5, Missour-1

Aten: Fror. I. Van Bladel

Deft. of the vavy

office of Naval Res. Branch office

$1030 \mathrm{5}$. Green Street

Pasadena 1, Callfom1a

Brandeis tind versity

Walthan, Nassachusetts

Attn: Litrary

General blectric Company

Microwave Laboratory

Electronics Division

Stanford Indugtrial Fart

Falo Alto, Callfornds

Attn: Lithary

Smyth Resuarch As ociates

3030 Lth Avenue

San Diego 3, Caifornde

Attni Dr. John E. Smyth

Electrical Enel neering

Calif ornda Inst. Of Technology

Pasadena, California

Attns Dr. Georges C. Weill

Naval Research Laboratory

washineton $25,0 . C$.

Attn: Dr. Henry J. Paserini Code 5278 A

Dr. George Kear

10585 \%. Stelline Road

Cupertino, Calif ornia

Brooklyn Polytechnic

85 Livingston Street

Brocklyn, New York

Attn: Prof. Nathan Marcuvitz

Dept. of Electrical Engineering

Brooklyn Polytechnic

35 Livingston Street

Brooklyn, New York

Attn: Dr. Jerry Shmoys

Dept. of Mathemat1cs

Und versity of New Mexco

Albuquerque, New Mexdco

Attn: Dr. I. Kolodner

W.L. Maxon

460 West 34 th Street

New York, N.Y.

Attr: Dr. Horry Hochstadt 



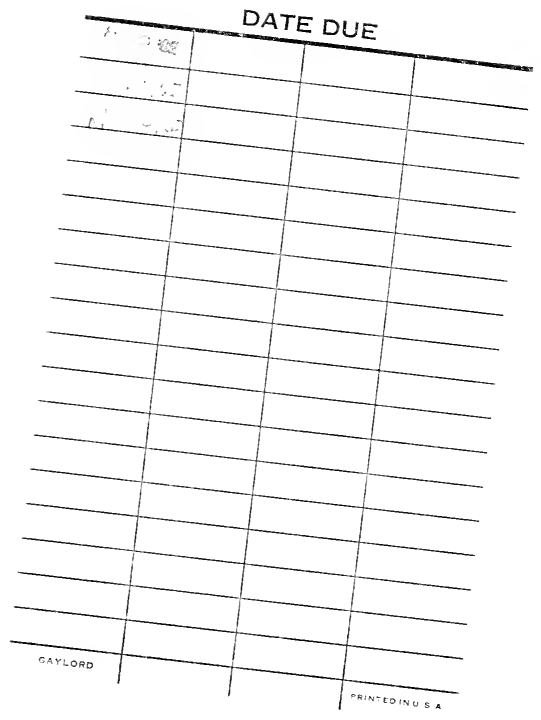


